\title{
Gambaran Kondisi Ibu Hamil dengan Diabetes Mellitus di RSD dr. Soebandi Jember Tahun 2013-2017 (Description of Pregnant Women Condition with Diabetes Mellitus in RSD dr. Soebandi Jember on 2013-2017)
}

\author{
Meggeria Dyah Matrika Tito Putri ${ }^{1}$, Pudjo Wahjudi ${ }^{2}$, Irma Prasetyowati ${ }^{3}$ \\ 'Bagian Epidemiologi dan Biostatistika Kependudukan \\ Fakultas Kesehatan Masyarakat, Universitas Jember \\ Jalan Kalimantan 37 Kampus Tegal Boto Jember 68121 \\ Email korespondensi: meggeriadyahm@gmail.com
}

\begin{abstract}
Diabetes Mellitus or diabetes is a chronic metabolic disease disorder caused by pancreas does not produce enough insulin or the body can't effectively use produced insulin. In pregnant women with a family history of diabetes mellitus, the prevalence of pregnancy with diabetes mellitus is $5.1 \%$. This research aim to determine description of pregnant women condition with diabetes mellitus in $R S D d r$. Soebandi Jember. This research used descriptive method with case series design. The sample size of 19 pregnant women with diabetes mellitus was selected by total sampling technique. The results showed that the high maternal age (52.6\%), low education (89.5\%), unemployment or housewife (89.2\%), had a genetic 78.9\%), BMI overweight (57.9\%), glucosuria (89.5\%), history of pre-eclampsia (57.9\%), low parity (79\%), never miscarried (84.2\%). Based on the result of the research, it was concluded that maternal education, maternal job, genetic, overweight BMI, glucosuria, and history of pre-eclampsia had an effect towards the occurrence of pregnant women with diabetes mellitus, also maternal age, parity and history of miscarriage had no effect on the occurrence of pregnant women with diabetes mellitus. To raise awareness of the risks of pregnancy with diabetes mellitus can be done with screening for diabetes mellitus.
\end{abstract}

Keywords: diabetes mellitus, pregnant women, RSD dr. Soebandi.

\begin{abstract}
Abstrak
Diabetes Mellitus atau disebut diabetes merupakan penyakit gangguan metabolik menahun akibat pankreas tidak memproduksi cukup insulin atau tubuh tidak dapat menggunakan insulin yang diproduksi secara efektif. Pada ibu hamil dengan riwayat keluarga diabetes mellitus, prevalensi kehamilan dengan diabetes mellitus sebesar $5,1 \%$. Penelitian ini bertujuan mengetahui gambaran kondisi ibu hamil dengan diabetes mellitus di RSD dr. Soebandi Jember. Penelitian ini menggunakan metode deskriptif dengan desain case series. Jumlah sampel 19 ibu hamil dengan diabetes mellitus yang dipilh dengan teknik total sampling. Hasil penelitian menunjukan bahwa usia ibu risiko tinggi (52,6\%), pendidikan rendah $(89,5 \%)$, tidak bekerja atau lbu Rumah Tangga $(89,2 \%)$, memiliki genetic $(78,9 \%)$, BMI overweight $(57,9 \%)$, glukosuria $(89,5 \%)$, riwayat pre-eklamsia $(57,9 \%)$, paritas rendah $(79 \%)$, tidak pernah mengalami keguguran $(84,2 \%)$. Berdasarkan hasil penelitian disimpulkan bahwa pendidikan ibu, pekerjaan ibu, genetik, BMl overweight, glukosuria, dan riwayat pre-eklamsia berpengaruh terhadap kejadian ibu hamil dengan diabetes mellitus serta usia ibu hamil, paritas dan riwayat keguguran tidak berpengaruh terhadap kejadian ibu hamil dengan diabetes mellitus. Untuk meningkatkan kewaspadaan terhadap risiko kehamilan dengan diabetes mellitus dengan pemeriksaan skrining diabetes mellitus.
\end{abstract}

Kata Kunci: diabetes mellitus, ibu hamil, RSD dr. Soebandi. 


\section{Pendahuluan}

Penyakit tidak menular (PTM) adalah penyebab kematian terbanyak di Indonesia. Kematian akibat PTM tidak hanya terjadi di perkotaan melainkan juga pedesaan [1]. Diabetes Mellitus (DM) atau disebut diabetes merupakan penyakit gangguan metabolik menahun akibat pankreas tidak memproduksi cukup insulin atau tubuh tidak dapat menggunakan insulin yang diproduksi secara efektif [2]. Diabetes mellitus merupakan satu dari tiga (anemia dan saluran kemih) komplikasi medis pada kehamilan yang paling sering. Terdapat beberapa tipe diabetes mellitus yaitu tipe 1 (bergantung insulin), tipe 2 (tidak bergantung insulin) dan Diabetes Mellitus Gestasional [3].

DM tipe 2 merupakan jenis DM yang paling banyak di temukan yaitu lebih dari 90-95\% [4]. Diabetes dalam kehamilan dibagi menjadi 2 macam yaitu diabetes overt (didiagnosa sejak sebelum hamil) dan diabetes gestasional (didiagnosa saat kehamilan). Diabetes gestasional didefinisikan sebagai intoleransi karbohidrat dengan tingkat keparahan bervariasi dan pertama kali diketahui saat kehamilan. Sebagian besar wanita dengan diabetes gestasional sudah menderita diabetes overt yang belum terdeteksi [3].

lbu hamil dengan diabetes mellitus merupakan diabetes mellitus tipe 2 dimana diabetes mellitus tipe 2 adalah gangguan ketika produksi insulin oleh pankreas tidak mencukupi, atau ketika sel-sel tubuh tidak merespon insulin (resistensi insulin) [3]. Diabetes mellitus dengan kehamilan pada teori yang lain mengatakan bahwa diabetes tipe 2 ini disebut sebagai "unmasked" atau baru ditemukan saat hamil dan patut dicurigai pada wanita yang memiliki ciri gemuk, riwayat keluarga diabetes, riwayat melahirkan bayi $>4 \mathrm{~kg}$, riwayat bayi lahir mati, dan riwayat abortus berulang. Diabetes Mellitus pada kehamilan melibatkan suatu kombinasi dari kemampuan reaksi dan pengeluaran hormon insulin yang tidak cukup. Intoleransi glukosa dapat terjadi dapat kambuh kembali pada kehamilan berikutnya dan 30-40\% akan mengalami diabetes yang nyata (diabetes tipe 2) khususnya jika obesitas [5].

International Diabetes Federation (IDF) memperkirakan bahwa sebanyak 183 juta orang tidak menyadari bahwa mereka mengidap DM. Sebesar $80 \%$ orang dengan DM tinggal di negara berpenghasilan rendah dan menengah. Pada tahun 2006, terdapat lebih dari 50 juta orang yang menderita DM di Asia Tenggara. Jumlah penderita DM terbesar berusia antara 40-59 tahun. Penderita DM pada tahun 2004 adalah 240 juta orang di seluruh dunia dan diperkirakan meningkat menjadi 380 juta penderita pada tahun 2025 dengan $80 \%$ beban kesehatan di negara berkembang dan negara miskin. Lebih dari $60 \%$ penderita DM berada di Asia dengan jumlah penderitamencapai 110 juta di tahun 2007 bdan prevalensinya diperkirakan akan meningkat pesat sebagai akibat adanya globalisasi [1].

World Health Organization (WHO) memprediksi adanya peningkatan jumlah penyandang DM di Indonesia dari 8,4 juta pada tahun 2000 menjadi sekitar 21,3 juta pada tahun 2030 [1]. Prevalensi DM meningkat sesuai dengan bertambahnya usia. Prevalensi DM lebih tinggi pada individu yang mempunyai berat badan lebih dan obesitas, pada kelompok hipertensi dan pada kelompok yang mempunyai aktifitas fisik kurang [2]. Menurut laporan Riskesdas tahun 2013, Provinsi Jawa Timur merupakan salah satu wilayah di Indonesia dengan prevalensi penderita DM sebesar $2,1 \%$ [6].

RSD dr. Soebandi adalah rumah sakit milik Pemerintah Daerah. RSD dr. Soebandi ditetapkan menjadi rumah sakit pusat rujukan bagian timur Provinsi Jawa Timur yang meliputi empat Kabupaten yaitu Kabupaten Banyuwangi, Situbondo, Bondowoso, dan Lumajang. Kasus ibu hamil dengan diabetes mellitus di RSD $\mathrm{dr}$. Soebandi dari tahun ke tahun terus meningkat. Ibu hamil dengan diabetes mellitus mempunyai dampak buruk yang cukup mengkhawatirkan dan berisiko terhadap ibu dan janin yang dikandung sampai dapat menyebabkan kematian ibu dan janin, oleh karena itu perlu deteksi sedini mungkin faktor risiko pada ibu hamil, serta kondisi ibu hamil dengan diabetes mellitus.

\section{Metode Penelitian}

Jenis penelitian yang digunakan adalah penelitian deskriptif kuantitatif dengan desain case series. Penelitian dilakukan di RSD dr. Soebandi Jember menggunakan data rekam medik pasien ibu hamil dengan Diabetes Mellitus tahun 2013-2017 yang berjumlah 19 responden. Penentuan sampel penelitian dengan menggunakan teknik total sampling yaitu teknik penentuan sampel dengan cara mengambil seluruh anggota populasi sebagai responden atau sampel. Variabel penelitian ini meliputi karakteristik pasien (usia ibu, pendidikan ibu, dan pekerjaan ibu), genetik (riwayat keluarga DM), riwayat obesitas, glukosuria, riwayat pre 
eklamsia, paritas dan riwayat keguguran. Sumber data penelitian adalah data sekunder. Data sekunder yaitu data jumlah data keseluruhan dan data rekam medik individu pasien ibu hamil rawat jalan RSD dr. Soebandi Jember dari tahun 2013-2017 yang terdiagnosis Diabetes Mellitus. Teknik pengumpulan data menggunakan studi dokumentasi. Analisis data yang dilakukan menggunakan statistik deskriptif.

\section{Hasil Penelitian}

Dari data yang telah diuraiakan dalam latar belakang maka didapatkan hasil karakteristik pasien yang meliputi usia ibu, pendidikan ibu, dan pekerjaan ibu serta kondisi ibu hamil dengan diabetes mellitus yang meliputi genetik/riwayat keluarga DM, obesitas, glukosuria, riwayat preeklamsia, parita, dan riwayat keguguran di RSD dr. Soebandi Jember sebagai berikut:

\section{Karakteristik Pasien Ibu Hamil dengan Diabe- tes Mellitus di RSD dr. Soebandi Jember}

Karakteristik pasien ibu hamil dengan diabetes mellitus meliputi usia ibu, pendidikan ibu dan pekerjaan ibu. Berikut karakteristik pasien berdasarkan usia ibu, pendidikan ibu, dan pekerjaan ibu disajikan dalam Tabel 1.

Tabel 1. Distribusi karakteristik pasien berdasarkan usia ibu, pendidikan ibu, dan pekerjaan ibu

\begin{tabular}{clcc}
\hline No. & Karakteristik Pesien & $\mathbf{n}$ & (\%) \\
\hline \multirow{2}{*}{1} & Usia Ibu & & \\
& Usia risiko tinggi & 10 & 52,6 \\
& Usia risiko rendah & 9 & 47,4 \\
\cline { 2 - 4 } & Total & 19 & 100 \\
\hline \multirow{2}{*}{2} & Pendidikan Ibu & & \\
& Pendidikan dasar/rendah & 17 & 89,5 \\
& Pendidikan menengah & 2 & 10,5 \\
& Pendidikan tinggi & - & - \\
\cline { 2 - 4 } & Total & 19 & 100 \\
\hline \multirow{2}{*}{3} & Pekerjaan Ibu & 3 & 15,8 \\
& Bekerja & 16 & 84,2 \\
\cline { 2 - 4 } & Tidak bekerja (IRT) & 71 & 100 \\
\cline { 2 - 4 } & \multicolumn{1}{c}{ Total } &
\end{tabular}

Tabel 1 menunjukkan bahwa pasien yang paling banyak berada pada rentang usia risiko tinggi $<20$ tahun atau $>35$ tahun sebanyak 10 pasien $(52,6 \%)$, kemudian pada rentang usia risiko rendah 20-35 tahun sebanyak 9 pasien $(47,4 \%)$. Pasien berdasarkan pendidikan ibu paling banyak yaitu lulusan pendidikan dasar/rendah (SD-SMP/MTs) sebanyak 17 pasien $(89,5 \%)$. Sedangkan lulusan pendidikan menengah (SMA/SMK) sebanyak 2 pasien $(10,5 \%)$, dan tidak ada pasien yang lulusan pendidikan tinggi (D3/S1). Pasien berdasarkan pekerjaan ibu paling banyak yaitu tidak bekerja atau sebagai lbu Rumah Tangga (IRT) sebanyak 16 pasien $(89,2 \%)$. Sedangkan ibu yang bekerja sebanyak 3 pasien (15,8\%).

\section{Kondisi lbu Hamil dengan Diabetes Mellitus Berdasarkan Genetik/Riwayat Keluarga DM}

Tabel 2. Kondisi ibu hamil dengan diabetes mellitus berdasarkan genetik/riwayat keluarga DM

\begin{tabular}{ccc}
\hline Riwayat Keluarga Diabetes Mellitus & $\mathbf{n}$ & $\%$ \\
\hline Ada yang menderita DM & 15 & 78,9 \\
Tidak ada yang menderita DM & 4 & 21,1 \\
\hline Total & 19 & 100 \\
\hline
\end{tabular}

Tabel 2 menunjukkan bahwa kondisi ibu hamil dengan diabetes mellitus berdasarkan genetik/riwayat keluarga DM paling banyak ada riwayat keluarga yang menderita DM yaitu sebanyak 15 pasien $(78,9 \%)$ dari total 19 pasien. Sedangkan, tidak ada riwayat keluarga yang menderita DM yaitu sebanyak 4 pasien $(21,1 \%)$.

Tabel 3. Kondisi ibu hamil dengan diabetes mellitus berdasarkan obesitas

\begin{tabular}{ccc}
\hline Obesitas & $\mathrm{n}$ & $\%$ \\
\hline Underweight: $<18,5 \mathrm{~kg} / \mathrm{m}^{2}$ & - & - \\
Normal: $18,5-22,9 \mathrm{~kg} / \mathrm{m}^{2}$ & 8 & $42,1 \%$ \\
Overweight $: 23-24,9 \mathrm{~kg} / \mathrm{m}^{2}$ & 11 & $57,9 \%$ \\
Obese: $\geq 25 \mathrm{~kg} / \mathrm{m}^{2}$ & - & - \\
\hline Total & 19 & 100 \\
\hline
\end{tabular}

Tabel 3 menunjukkan bahwa kondisi ibu hamil dengan diabetes mellitus berdasarkan obesitas paling banyak pada ibu hamil yang BMI overweight $\left(23-24,9 \mathrm{~kg} / \mathrm{m}^{2}\right)$ yaitu sebanyak 11 pasien $(57,9 \%)$ dari total 19 pasien. Sedangkan, ibu hamil yang BMI normal $\left(18,5-22,9 \mathrm{~kg} / \mathrm{m}^{2}\right)$ yaitu sebanyak 8 pasien $(42,1 \%)$.

Tabel 4. Kondisi ibu hamil dengan diabetes mellitus berdasarkan glukosuria

\begin{tabular}{lccc}
\hline & Glukosuria & $\mathrm{n}$ & $\%$ \\
\hline $\mathrm{Ya}$ & & 17 & 89,5 \\
Tidak & & 2 & 10,5 \\
\hline & Total & 19 & 100 \\
\hline
\end{tabular}

Tabel 4 menunjukkan bahwa kondisi ibu hamil dengan diabetes mellitus berdasarkan glukosuria paling banyak yaitu ibu hamil yang terkena glukosuria sebanyak 17 pasien $(89,5 \%)$ dari total 19 pasien. Sedangkan, ibu hamil yang tidak terkena glukosuria yaitu sebanyak 2 pasien $(10,5 \%)$. 
Tabel 5. Kondisi ibu hamil dengan diabetes mellitus berdasarkan riwayat pre-eklamsia

\begin{tabular}{lccc}
\hline & Riwayat Pre-eklamsia & $\mathrm{n}$ & $\%$ \\
\hline Ya & & 11 & 57,9 \\
Tidak & & 8 & 42,1 \\
\hline & Total & 19 & 100 \\
\hline
\end{tabular}

Tabel 5 menunjukkan bahwa kondisi ibu hamil dengan diabetes mellitus berdasarkan riwayat pre-eklamsia paling banyak pada ibu hamil yang memiliki riwayat pre-eklamsia yaitu sebanyak 11 pasien (57,9\%) dari total 19 pasien. Sedangkan, ibu hamil yang tidak memiliki riwayat pre-eklamsia yaitu sebanyak 8 pasien $(42,1 \%)$.

Tabel 6. Kondisi ibu hamil dengan diabetes mellitus berdasarkan paritas

\begin{tabular}{lcc}
\hline \multicolumn{1}{c}{ Paritas } & $\mathrm{n}$ & $\%$ \\
\hline Risiko Tinggi (Paritas 1 dan paritas & 4 & $21 \%$ \\
tinggi/lebih dari 3) & 15 & $79 \%$ \\
\hline Risiko Rendah (Paritas 2-3) & 19 & 100 \\
\hline Total &
\end{tabular}

Tabel 6 menunjukkan bahwa kondisi ibu hamil dengan diabetes mellitus berdasarkan paritas paling banyak pada ibu hamil yang memiliki risiko rendah (paritas 2-3) yaitu sebanyak 15 pasien (79\%) dari total 19 pasien. Sedangkan, ibu hamil yang memiliki risiko tinggi (paritas 1 dan paritas tinggi/lebih dari 3) yaitu sebanyak 4 pasien (21\%).

Tabel 7. Kondisi ibu hamil dengan diabetes mellitus berdasarkan riwayat keguguran

\begin{tabular}{ccc}
\hline Riwayat Keguguran & $\mathrm{n}$ & $\%$ \\
\hline Pernah keguguran & 3 & 15,8 \\
Tidak pernah keguguran & 16 & 84,2 \\
\hline Total & 19 & 100 \\
\hline
\end{tabular}

Tabel 7 menunjukkan bahwa kondisi ibu hamil dengan diabetes mellitus berdasarkan riwayat keguguran paling banyak pada ibu hamil yang tidak pernah mengalami keguguran yaitu sebanyak 16 pasien $(84,2 \%)$ dari total 19 pasien. Sedangkan, ibu hamil yang pernah mengalami keguguran yaitu sebanyak 3 pasien $(15,8 \%)$.

\section{Pembahasan}

\author{
Karakteristik Pasien Ibu Hamil dengan \\ Diabetes Mellitus di RSD dr. Soebandi Jember \\ Penentuan usia didapatkan dari data \\ rekam medik pasien saat penelitian, terhitung \\ sejak dilahirkan sampai dengan pada saat
}

kehamilan terakhir yang tercatat dalam data rekam medik. Pasien yang paling banyak berada pada rentang usia risiko tinggi yaitu $<20$ tahun atau $>35$ tahun sebanyak 10 pasien $(52,6 \%)$. Pada usia $<18$ tahun, keadaan alat reproduksi belum siap untuk menerima kehamilan. Hal ini akan meningkatkan terjadinya keracunan kehamilan. Sedangkan pada usia 35 tahun atau lebih, rentan terjadinya berbagai penyakit dalam bentuk hipertensi, dan eklamsia [7]. Hal ini disebabkan karena terjadinya perubahan pada jaringan alat-alat kandungan dan jalan lahir tidak lentur lagi [7]. Hasil penelitian ini sejalan dengan hasil penelitian lain yang didapatkan hasil bahwa umur ibu hamil $\geq 35$ tahun berisiko 4,05 kali untuk menderita diabetes melitus gestasional dibandingkan dengan umur ibu hamil $<35$ tahun [8]. Diabetes melitus merupakan penyakit yang terjadi akibat penurunan fungsi organ tubuh (degeneratif) terutama gangguan organ pankreas dalam menghasilkan hormon insulin, sehingga DM akan meningkat kasusnya sejalan dengan pertambahan usia [9].

Pendidikan ibu paling banyak yaitu lulusan pendidikan dasar/rendah (SD-SMP/MTs) sebanyak 17 pasien (89,5\%). Secara teori tingkat pendidikan ikut menentukan atau mempengaruhi mudah tidaknya seseorang menerima suatu pegetahuan, semakin tinggi tingkat pedidikan semakin baik pula tingkat pengetahuan yang dimiliki seseorang [9]. Hasil dari data rekam medik pasien menunjukkan bahwa tingkat pendidikan responden paling banyak adalah lulusan pendidikan dasar/rendah (SD-SMP/MTs) sehingga tingkat pegetahuan responden masuk kedalam kategori rendah. Hal ini berpengaruh pada pengetahuan ibu mengenai pola konsumsi yang benar untuk ibu hamil dengan diabetes mellitus. Semakin rendah pendidikan ibu, semakin rendah pula tingkat pengetahuan mengenai pola makan dan hal-hal lainnya yang harus dihindari dan yang harus dilakukan oleh ibu hamil dengan diabetes mellitus. Hasil penelitian ini tidak sejalan dengan hasil penelitian bahwa terdapat peningkatan prevalensi ibu hamil dengan diabetes mellitus yang signifikan dengan meningkatnya tingkat pendidikan [9]. Pada studi lainnya Yang et al tidak menemukan hubungan antara ibu hamil dengan diabetes mellitus dan pendidikan pada wanita hamil di Cina.

Jenis pekerjaan juga erat kaitannya dengan kejadian DM. Pekerjaan seseorang mempengaruhi tingkat aktivitas fisiknya. Semakin berat pekerjaan, semakin berat juga aktivitas fisiknya, contoh pekerjaan berat seperti buruh, petani, PNS, dah pegawai swasta. Hasil 
penelitian menunjukkan bahwa pekerjaan ibu paling banyak yaitu tidak bekerja atau sebagai Ibu Rumah Tangga (IRT) sebanyak 16 pasien $(89,2 \%)$. Penelitian ini diperkuat penelitian sebelumnya tentang aktivitas fisik berdampak terhadap aksi insulin pada orang yang beresiko diabetes mellitus [10]. Kurangnya aktivitas merupakan salah satu faktor yang ikut berperan meyebabkan resistensi insulin pada diabetes melitus. Individu yang aktif memiliki insulin dan profil glukosa yang lebih baik dari pada individu yang tidak aktif. Hasil penelitian ini diperkuat dengan penelitian sebelumnya dimana pola aktivitas fisik dengan kadar gula darah ada hubungan karena responden dengan pola aktivitas ringan dapat mengakibatkan meningkatnya kadar gula darah [11].

\section{Kondisi lbu Hamil dengan Diabetes Mellitus di RSD dr. Soebandi Jember}

Riwayat penyakit keluarga dapat menjadi pendeteksi bagi orang yang memiliki keluarga dengan diabetes mellitus. Kondisi ibu hamil dengan diabetes mellitus berdasarkan genetik/riwayat keluarga DM paling banyak ada riwayat keluarga yang menderita DM yaitu sebanyak 15 pasien (78,9\%) dari total 19 pasien. Hasil penelitian ini sejalan dengan penelitian lain yaitu antara riwayat keluarga DM dengan kejadian penyakit diabetes melitus gestasional bahwa ada hubungan yang signifikan [12]. Penelitian lain bahwa ada hubungan antara riwayat penyakit keluarga dengan kejadian diabetes mellitus [13]. Namun penelitian ini tidak sejalan dengan penelitian oleh Pamolango bahwa ibu hamil yang tidak memiliki riwayat DM pada keluarga 2,3 kali lebih beresiko untuk terkena DM kehamilan dibandingkan ibu hamil yang memiliki riwayat DM pada keluarga [14].

Obesitas adalah agen utama dan faktor penyebab ibu hamil dengan diabetes mellitus. Lemak sub kutan dan visceral pada tubuh ibu calon hamil dengan obesitas, akan menghasilkan hormon adipositokin yang melawan kerja insulin. Hasil penelitian diketahui bahwa kondisi ibu hamil dengan diabetes mellitus berdasarkan obesitas paling banyak pada ibu hamil yang BMI overweight $\left(23-24,9 \mathrm{~kg} / \mathrm{m}^{2}\right)$ yaitu sebanyak 11 pasien $(57,9 \%)$ dari total 19 pasien. Sedangkan, ibu hamil yang BMI normal $\left(18,5-22,9 \mathrm{~kg} / \mathrm{m}^{2}\right)$ yaitu sebanyak 8 pasien $(42,1 \%)$. Riwayat overweight juga merupakan salah satu faktor yang dapat berkontribusi secara tidak langsung pada kejadian prediabetes/ diabetes mellitus gestasional. Hasil uji statistik menunjukkan bahwa ibu hamil yang memiliki riwayat overweight berisiko 6,952 kali menderita prediabetes/diabetes mellitus gestasional diabandingkan dengan ibu hamil yang tidak memiliki riwayat overweight dimana nilai besar risiko tersebut bermakna secara statistic [15]. Hasil penelitian ini sejalan dengan hasil penelitian dimana didapatkan hasil bahwa, ibu yang memiliki riwayat overweight berisiko 1,53 kali untuk menderita diabetes mellitus gestasional sedangkan ibu yang memiliki risiko obesitas berisiko 2,59 kali untuk menderita diabetes mellitus gestasional dibandingkan dengan ibu yang tidak memiliki riwayat overweight [8].

Gangguan pada kerja insulin, baik secara kualitas maupun kuantitas keseimbangan tersebut akan terganggu dan kadar glukosa darah akan meningkat, kelebihan glukosa akan dikeluarkan melalui urin sehingga terjadi glukosuria. Kondisi ibu hamil dengan diabetes mellitus berdasarkan glukosuria paling banyak yaitu ibu hamil yang terkena glukosuria sebanyak 17 pasien $(89,5 \%)$ dari total 19 pasien. Hasil ini tidak sesuai dengan teori dimana kadar glukosa darah pada ibu hamil dengan diabetes mellitus tinggi seharusnya kadar glukosa dalam urin juga tinggi. Dimungkinkan pada 2 pasien yang tidak terkena glukosuria, datanya tidak tertulis pada buku rekam medik, namun sebenarnya pasien tersebut juga terkena glukosuria.

Kondisi ibu hamil dengan diabetes mellitus berdasarkan riwayat pre-eklamsia paling banyak pada ibu hamil yang memiliki riwayat preeklamsia yaitu sebanyak 11 pasien $(57,9 \%)$ dari total 19 pasien. Sedangkan, ibu hamil yang tidak memiliki riwayat pre-eklamsia yaitu sebanyak 8 pasien (42,1\%). Penyakit diabetes mellitus terjadi peningkatan substansial risiko pada ibu dan janin [16]. Risiko pada ibu mencakup kerusakan retina, ginjal, dan jantung, infeksi saluran kemih, ketoasidosis diabetes, dan seksio sesarea. Hipertensi sering dijumpai dan wanita diabetes dengan penyakit ginjal sehingga beresiko tinggi mengalami pre-eklamsia. Pendapat ini juga diperkuat bahwa diabetes mellitus gestasional merupakan gangguan metabolisme pada kehamilan yang ringan, tetapi hiperglikemia ringan dapat memberikan penyulit pada ibu berupa pre-eklamsia [17]. Hal ini terjadi dimungkinkan karena adanya riwayat kejadian pre-eklamsia yang lalu untuk ibu hamil multipara dan grandemultipara yaitu pada kehamilan yang dulu mempunyai riwayat pre-eklamsia sehingga berisiko terjadinya pre-eklamsia untuk kehamilan selanjutnya.

Paritas yang tinggi akan berdampak pada timbulnya berbagai masalah kesehatan baik bagi 
ibu maupun bayi yang dilahirkan. Kehamilan dan persalinan yang berulang-ulang menyebabkan kerusakan pembuluh darah di dinding rahim dan kemunduran daya lentur (elastisitas) jaringan yang sudah berulang kali diregangkan kehamilan sehingga cenderung timbul kelainan letak ataupun kelainan pertumbuhan plasenta dan pertumbuhan janin. Hasil penelitian diketahui bahwa kondisi ibu hamil dengan diabetes mellitus berdasarkan paritas paling banyak pada ibu hamil yang memiliki risiko rendah (paritas 2-3) yaitu sebanyak 15 pasien $(79 \%)$ dari total 19 pasien. Sedangkan, ibu hamil yang memiliki risiko tinggi (paritas 1 dan paritas tinggi/lebih dari 3) yaitu sebanyak 4 pasien (21\%). Penelitian ini sejalan dengan penelitian Istiarti bahwa tidak ada hubungan antara paritas ibu hamil dengan kejadian diabetes mellitus dengan kehamilan, hal ini disebabkan bahwa paritas bukan satu-satunya faktor penyebab diabetes mellitus dengan kehamilan melainkan ada faktor lain yaitu faktor dasar (sosial ekonomi, pengetahuan, pendidikan dan budaya) dan faktor langsung (pola konsumsi, penyakit infeksi) [18]. Penelitian menyatakan bahwa jumlah paritas tidak berhubungan dengan kejadian asfiksia neonatorum [19].

Pada ibu hamil dengan diabetes melitus, jumlah insulin kurang atau tidak berfungsi sehingga siklus Kreb tidak berlangsung dengan baik. Metabolisme terbalik terjadi sehingga akan dijumpai hiperglikemia pada maternal yang akan berpengaruh terhadap janin [16]. Kondisi ibu hamil dengan diabetes mellitus berdasarkan riwayat keguguran paling banyak pada ibu hamil yang tidak pernah mengalami keguguran yaitu sebanyak 16 pasien $(84,2 \%)$ dari total 19 pasien. Hasil penelitian ini tidak sejalan dengan teori yang ada karena dimungkinkan ibu hamil yang tidak pernah mengalami keguguran memiliki faktor risiko lain yang lebih dominan sehingga mengakibatkan ibu tersebut terdiagnosis diabetes mellitus.

\section{Simpulan dan Saran}

Kesimpulan pada penelitian ini adalah sebagian besar usia ibu termasuk risiko tinggi yaitu $<20$ tahun atau >35 tahun, berpendidikan dasar/rendah, bekerja sebagai ibu rumah tangga. Kondisi ibu hamil yang berpengaruh terhadap kejadian ibu hamil dengan diabetes mellitus adalah genetik/riwayat keluarga DM, obesitas ibu hamil dengan BMI overweight, glukosuria, dan riwayat pre-eklamsia. Kondisi ibu hamil yang tidak berpengaruh terhadap kejadian ibu hamil dengan diabetes mellitus adalah paritas dan riwayat keguguran.

Berdasarkan hasil kesimpulan saran yang dapat diberikan yaitu meningkatkan peran Puskesmas dalam pemberian arahan kepada ibu hamil dengan diabetes mellitus untuk aktif melakukan pemeriksaaan kesehatannya supaya dapat meminimalisir dampak buruk dari diabetes mellitus tersebut. Selain itu lebih aktif dalam memberikan pendidikan kesehatan bagi ibu hamil tentang kehamilan dengan DM dan faktor risiko yang mempengaruhinya sebab masih banyak ibu hamil yang berpendidikan rendah serta meningkatkan program skrining diabetes mellitus.

\section{Daftar Pustaka}

[1]. Kemenkes. 2012. Buletin Jendela Data dan Informasi Kesehatan Penyakit Tidak Menular. Jakarta: Kementerian Kesehatan Republik Indonesia.

[2]. Infodatin. 2014. Diabetes. [serial online]. http://www.depkes.go.id/resources/downlo ad/pusdatin/infodatin/infodatindiabetes.pdf [25 April 2017].

[3]. Tandra, Hans. 2014. Strategi Mengalahkan Komplikasi Diabetes dari kepala sampai kaki. Jakarta: PT Gramedia Pustaka Utama.

[4]. American Diabetes Association. 2015. Diagnosis and classification of diabetes mellitus. Diabetes care. Vol. 29(S1):5-10. [serial online]. http://phc.mui.ac.ir/sites/phc.mui.ac.ir/files /daryaft-

file/8)\%20ADA\%20Diagnosis\%20and\%20 Classification\%20of\%20Diabetes\%20Melli tus.pdf [27 April 2017].

[5]. Greenspan, Francis S. \& Baxter, John D. 2001. Endokrinologi Dasar \& Klinik. Edisi 4. Jakarta: EGC.

[6]. Riskesdas. 2013. Riset Kesehatan Dasar. Jakarta: Badan Penelitian dan Pengembangan Kesehatan Kementerian Kesehatan RI.

[7]. Rochjati, P., 2003. Skrining Antenatal Pada Ibu Hamil. Surabaya.

[8]. Hosler et al. 2011. Stressful events, smoking exposure and other maternal risk factors associated with gestational diabetes mellitus. Journal of Paediatric and Perinatal Epidemiology. No. 25: 566-574. [serial online]. https://www.ncbi.nlm.nih.gov/pubmed/219 
[9]. $\quad$ 80946 [2 Mei 2017].

[10]. Zahtamal, dkk. 2007. Faktor-Faktor Risiko Pasien Diabetes Mellitus. Riau: FK Universitas Riau; Vol. 23, No. 3, Halaman 142-147. [serial online] https://media.neliti.com/media/publication s/163844-ID-faktor-faktor-risiko-pasiendiabetes-mel.pdf [4 Oktober 2017

[11]. Kriska, A. 2007. Physical activity and the prevention of type II (Non-insulin dependen) diabetes. [serial online]. http://www.fitness.gov/diabetes.pdf $\quad$ [4 Oktober 2017].

[12]. Paramitha, M.G. 2014. Hubungan Aktivitas Fisik dan Kadar Gula Darah Pada Pasien Diabetes Mellitus Tipe II di RSUD Karanganyer. Jurnal Fakultas Kedokteran Muhammadiyah Surakarta.

[13]. Trisnawati, Shara Kurnia dan Setyorogo, Soedijono. 2013. Faktor Risiko Kejadian Diabetes Melitus Tipe II Di Puskesmas Kecamatan Cengkareng Jakarta Barat Tahun 2012. Jurnal IImiah Kesehatan, 5(1).

[14]. Etika, Arif Nurma dan Monalisa, Via. 2016. Riwayat Penyakit Keluarga dengan Kejadian Diabetes Mellitus. Jurnal Care; Vol. 4, No.1.

[15]. Pamolango, Wantouw \& Sambeka. 2013. Hubungan Riwayat Diabetes Mellitus pada Keluarga dengan Kejadian Diabetes Mellitus Gestasional pada Ibu Hamil di PKM Bahu Kec. Malalayang Kota Manado. Manado: Universitas Sam Ratulangi ejournal keperawatan (e-Kp). Vol. 1, No. 1. [serial online]. https://ejournal.unsrat.ac.id/index.php/jkp/ article/view/2203 [24 April 2017].

[16]. Pratama, Wahiduddin \& Sidik. 2008. Faktor Risiko Kejadian Prediabetes/ Diabetes Melitus Gestasional Di RSIA Sitti Khadijah I Kota Makassar. [serial online]. http://repository.unhas.ac.id/bitstream/han dle/123456789/4298/IFAN\%20PRATAMA $\% 20 \mathrm{SALDAH}$ K11109020.pdf? sequence $=$ 1 [24 April 2017].

[17]. Cunningham, FG., et al. 2013. Obstetri Williams (Williams Obstetri). Jakarta: EGC.

[18]. Saifuddin, Abdul Bahri. 2008. Pelayanan Kesehatan Maternal Dan Neonatal. Jakarta : Bina Pustaka.

[19]. Istiarti, Tinuk. 2000. Menanti Buah Hati. Yogyakarta: Media Persindo.

[20]. Gilang., Notoatmojo R., dan Rakhmawatie
M.D. 2015. Faktor-faktor yang berhubungan dengan Kejadian Asfiksia Neonatorum (Studi Di RSUD Tugurejo Semarang). Fakultas Kedokteran Universitas Muhammadiyah Semarang. 